\title{
The Check Your Cannabis Screener: A New Online Personalized Feedback Tool
}

\author{
John A. Cunningham ${ }^{*}, 1$ and Trevor van Mierlo² \\ ${ }^{I}$ Centre for Addiction and Mental Health and University of Toronto, Canada \\ ${ }^{2}$ Evolution Health Systems Inc., Canada
}

\begin{abstract}
This brief report describes the development and first year of use of an Internet-based screener for Cannabis users. Two versions of the Check Your Cannabis screener were compared, one linked to an already established harm reduction website for young Cannabis users (as an exercise called "Check how I compare with others," on www.WhatsWithWeed.ca) and the other a standalone version (www.CheckYourCannabis.net). The What's With Weed version attracted ten times more users and had a significantly younger audience as compared to the standalone version, underlining the benefits of targeting a website to a specific audience and linking to websites with already established reputations. Further work is needed to establish any impact on actual Cannabis use from taking the Check Your Cannabis screener.
\end{abstract}

\section{INTRODUCTION}

Cannabis is the most commonly used illicit drug in Canada [1]. There are clear negative consequences to the use of Cannabis from a health and psychosocial perspective $[2,3]$. Primarily, Cannabis displays a clear dose-response curve in which the more frequently people use Cannabis, the more likely they are to experience negative consequences from this use [4]. In addition, there is an accumulating body of evidence on the connection cannabis use to the onset of schizophrenia among vulnerable populations [5].

A particular concern with Cannabis is that it is a drug most often used by young adults [6]. As a means of harm reduction amongst this population, a recent Canadian initiative developed a website called 'What's with weed?' (www.WhatsWithWeed.ca) [7]. The website focuses on young adults, takes a harm reduction perspective, and allows the participant to make an informed choice about their Cannabis use. The Internet is an excellent method for providing this service to young adults, given the high proportion of teenagers who use the Internet on a regular basis, the low cost of providing the service once it is developed, and the anonymous nature of the website $[8,9]$.

A new tool commissioned for this website is the Check Your Cannabis (CYC) screener. This screener allows the participant to answer a few questions about their cannabis use and then receive personalized feedback about how their Cannabis use compares to others of the same age and sex and also, provides a test of the severity of the participant's cannabis use. The goal of the CYC screener is to allow participants to evaluate their own Cannabis use in a nonjudgmental setting and with a harm reduction perspective. To our knowledge, this is the first screener of its type for

*Address correspondence to this author at the Centre for Addiction and Mental Health, 33 Russell Street, Toronto, Ontario, M5S 2S1, Canada;

Tel: 416-535-8501, Ext. 6701; Fax: 416-595-6899;

E-mail: John_Cunningham@camh.net
Cannabis users. The CYC screener was developed within the context of the literature on the benefits of normative feedback (i.e., providing a comparison of how much the participant consumes to how much others consume). While no published work exists to-date that demonstrates the benefits of normative comparisons for Cannabis users, there is a growing body of evidence on the impact of normative feedback on heavy drinkers, smokers, and even problem gamblers [1012].

The intent of this brief report is to describe the content of the CYC screener as well as the characteristics of the users of this screener in the first 12 months of its existence. In addition, comparisons will be made between the version of the CYC linked to the What's With Weed website to a stand alone version (www.CheckYourCannabis.net).

\section{METHODS}

\section{Content of the CYC Screener}

The Check Your Cannabis screener asks a brief set of questions and then provides the participant with a personalized feedback summary. The screener questions consist of demographic items (age, sex, country of origin), questions about frequency of Cannabis use in the last 12 months, amount of money spent on Cannabis, and the six items of the Alcohol, Smoking and Substance Involvement Screening Test (ASSIST), developed by the World Health Organization [13]. Finally, the front page of the screener: 1) asks the respondent why they are taking the test (for yourself, for someone you know, you are just checking out the test to see what the results look like); and 2) asks the participant to acknowledge that their data can be used for research purposes. Conduct of this study was approved by the standing ethics review committee of the Centre for Addiction and Mental Health.

Upon completing the screener, the participant is provided with a personalized feedback Final Report. The report consists of a pie chart and summary that compares the partici- 
pants' Cannabis use to others of the same age and sex. At the time of this study, only Canadian comparison data was available (derived from combined data set of the 2004, 2005, and 2006 Canadian Tobacco Use Monitoring Survey; age range 15 and over) [14]. However, US data is forthcoming (derived from the combined 2002 to 2007 National Houshold Survey on Drug Use and Health; age range 12 and over) [15] and there are plans to add other country data at a later date. The Final Report continues with a summary of how much the person spends on Cannabis and then concludes with the participant's ASSIST score along with an interpretation of what this score means about the severity of their Cannabis use. Please try the stand alone version of the CYC screener at www.CheckYourCannabis.net or the version attached to the What's With Weed website (the exercise, "Check how I compare with others"; www. WhatsWithWeed.ca) in order to see more details about the screener. Fig. (1) displays example feedback generated by the Check Your Cannabis website.

\section{Data Collection and Analysis}

A database of all participants on both these versions of the CYC screener was compiled for the first 12 months of the life of this screener. The database was downloaded and translated to SPSS [16] for analyses. Only participants who stated that they were taking the test for themselves were included in the full analysis.

\section{RESULTS}

There were 986 completed CYC tests in the first year of use, 901 from the What's With Weed site and 85 from the standalone site. Almost two thirds $(58.8 \%, \mathrm{~N}=580)$ stated that they were taking the test for themselves, while 8.7 $(\mathrm{n}=86)$ said they were taking the test for someone else and $32.5 \%(\mathrm{n}=320)$ said they were just checking out the test to see what the results looked like. There was no significant difference $(p>.05)$ in the proportion of participants who said they were taking the test for themselves between the two versions of the websites. The remaining results will only use data from the 580 tests where participants said they were taking the test for themselves (539 tests from the What's With Weed site and 41 from the standalone version).

There were no significant differences $(p>.05)$ in the proportion of male versus female participants in the two websites with $73.3 \%$ being male in the full sample $(n=580)$. However, there were significant differences in age and country of residence between the two websites with participants using the What's With Weed website being younger and more likely to reside in Canada as compared to the standalone version (Mean [SD] Age $=20.4$ [7.2] and 29.7 [12.4] respectively; t-test $=4.7, p=.001$; Proportion residing in Canada $=90.4 \%$ versus $63.4 \%$ respectively; $\chi^{2}=24.5,1 \mathrm{df}$, $p<.001$ ). Table 1 presents the demographic and Cannabis use characteristics for the participants of the two websites.

There were no significant differences $(p>.05)$ in frequency and severity of Cannabis use reported on the two websites. For the combined sample $(\mathrm{n}=580), 23.8 \%$ were categorized as high risk, $70.3 \%$ as moderate risk, and 5.9\% as low risk Cannabis users on the ASSIST scale. Frequency of Cannabis use was fairly high, with $50.0 \%$ reporting daily or almost daily Cannabis use in the last three months (24.5\% weekly use and $25.5 \%$ reporting less than weekly use). Finally, $41.3 \%$ reported spending $\$ 100$ per month or more on Cannabis use and $22.1 \%$ reported spending more than $\$ 100$ on one occasion at least once in the last 12 months.

\section{DISCUSSION}

The CYC provides participants with objective personalized feedback about their Cannabis use in a non-judgemental fashion. Participants of the website appeared to be frequent Cannabis users with moderate severity risk associated with their Cannabis use. One clear result from this study is the benefit of linking the screener to an already established website (What's With Weed). The standalone version was not advertised and was rarely used. In contrast, the What's With Weed version was used roughly ten times as often. In addition, linking to the What's With Weed site allowed targeting of the most relevant population - young Canadians (as only Canadian comparison data was available at the time of this study).

In designing the CYC screener, we were cognizant of the need for brevity as many users of the Internet tend to skip quickly from one page to another [17]. The CYC screener also took advantage of the availability of excellent population normative data that is available for use in Canada [14] and is also profiting from the availability of large, high quality data sets in the USA [15]. As normative data is added to the CYC from other countries it will be a challenge to find sufficiently large general population data sets that will allow the generation of accurate population summary data, separately for males and females, and for different age groups. In addition, the development of screeners, such as the ASSIST, by the World Health Organization has allowed for the inclusion of a brief, research-validated assessment that is relevant for participants in many different cultural settings [13].

Personalized feedback screeners, as well as other Internet-based interventions, have the goal of increasing the accessibility of services for those with addictions and other health concerns. Access to the Internet is widespread [18] and many people turn to the Internet for health information [19]. Many people with addictions concerns are unwilling or unable to access treatment and often cite reasons such as stigma or embarrassment, or the desire to deal with the problem on their own, as reasons for not seeking treatment [20, 21]. There is some evidence that Internet-based interventions are able to provide help to those traditionally underserved by face-to-face addictions treatment services [22]. The challenge then, is to continue to expand the range and accessibility of these online services in order to provide help to more people in need.

Future directions for the Check Your Cannabis screener will be to address some of the clear limitations of this preliminary report. Primarily, research is needed to develop an evidence base regarding any impact on Cannabis use from taking the screener and to establish the reliability of the selfreport data on this website. In addition, population comparison data will be added for more countries in order to make this globally accessible tool more relevant to all potential participants. 


\section{Cannaubìs}

Print Email

\section{Check Your Cannabis Final Report for Sam}

About $62.3 \%$ of 24 year old Canadian men have used cannabis, marijuana or hashish at least once in their lifetime. This pie chart shows how often 24 year old Canadian men have used cannabis, marijuana or hashish, ever, or in the last year:

The highlighted segment is where your cannabis use fits on the chart:

Cannabis, Marijuana or Hashish Use among 24 Year Old Canadian men

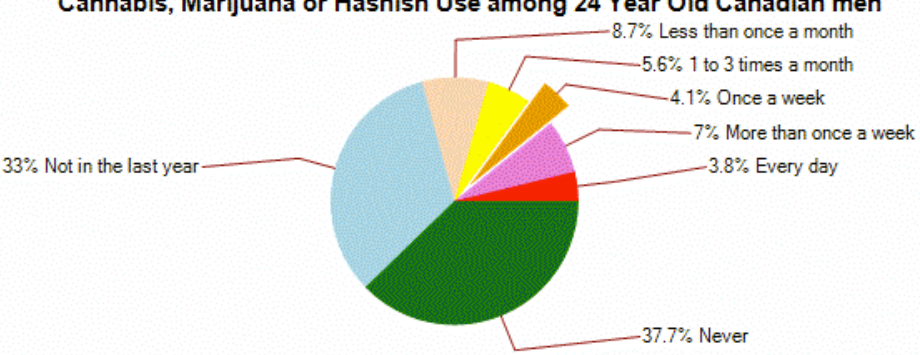

You use cannabis more often than $85.1 \%$ of 24 year old Canadian men.

How Much Do I Spend?

Based on the information you gave us, you spend approximately $\$ 100$ per month, or approximately $\$ 1200$ per year on cannabis, marijuana or hashish. The largest amount you reported spending on any given day in the past 12 months is $\$ 15$.

Your ASSIST Score

The Alcohol, Smoking and Substance Abuse Scoring (ASSIST) Test was developed by the World Health Organization (WHO) to evaluate a person's use of cannabis, marijuana or hashish. The ASSIST score shows whether a person's cannabis use should be considered a problem. Higher scores usually mean serious problems. The chart is in the shape of a pyramid to show that there are more people with low ASSIST scores than high ones.

Your ASSIST score is 9 . The white area of the chart shows where your score falls.

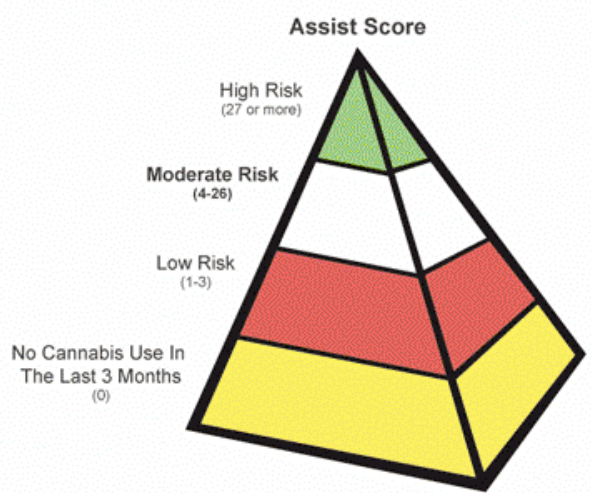

Here are the explanations of ASSIST scores:

\begin{tabular}{|l|l|l|}
\hline Score & Definition & Probably Life Consequences \\
\hline 0 & No risk & No cannabis use. \\
\hline $1-3$ & Low risk & $\begin{array}{l}\text { You are at low risk of health and other problems from your current } \\
\text { pattern of cannabis use. }\end{array}$ \\
\hline $4-26$ & Moderate risk & $\begin{array}{l}\text { You are at risk of health and other problems from your current } \\
\text { cannabis use. }\end{array}$ \\
\hline 27 or more & High risk & $\begin{array}{l}\text { You are at high risk of experiencing severe problems (health, social, } \\
\text { financial, legal, relationship) as a result of your current pattern of use } \\
\text { and are likely to be dependent on cannabis. }\end{array}$ \\
\hline
\end{tabular}

Logout

Evolution QHealth

Fig. (1). Example of final report generated by the check your Cannabis screener. 
Table 1. Demographic and Cannabis Use Characteristics of Users of Two Different Versions of the Check Your Cannabis Screener Website

\begin{tabular}{|c|c|c|c|}
\hline Variable & $\begin{array}{l}\text { What's With Weed Ver- } \\
\text { sion }(\mathbf{N}=\mathbf{5 3 9})\end{array}$ & $\begin{array}{c}\text { Stand Alone Beta } \\
\text { Version }(N=41)\end{array}$ & $p$ \\
\hline Mean $(S D)$ Age & $20.4(7.2)$ & $29.7(12.4)$ & .001 \\
\hline$\%$ Male & 73.7 & 68.3 & N.S. \\
\hline \% Located in Canada & 90.4 & 63.4 & .001 \\
\hline \multicolumn{4}{|l|}{$\%$ Frequency of Cannabis use, past 3 months } \\
\hline Daily or almost daily use & 50.5 & 43.9 & \\
\hline Weekly use & 25.0 & 17.1 & \\
\hline Less than weekly use & 24.5 & 39.0 & N.S. \\
\hline \multicolumn{4}{|l|}{$\%$ ASSIST score (Cannabis risk status) } \\
\hline High risk & 23.0 & 34.1 & \\
\hline Moderate risk & 71.1 & 61.0 & \\
\hline Low risk & 5.9 & 4.9 & N.S. \\
\hline$\%$ Spend $\$ 100$ or more per month on Cannabis & 40.5 & 57.7 & N.S. \\
\hline$\%$ Spend $>\$ 100$ or more on one occasion at least once in the past year & 24.4 & 34.6 & N.S. \\
\hline
\end{tabular}

\section{ACKNOWLEDGEMENTS}

This research has been supported by a grant from the Ontario Ministry of Health and Long-Term Care and by Parent Action on Drugs (the creator of the What's With Weed website). The views expressed here do not necessarily reflect those of the Ministry nor of Parent Action on Drugs.

\section{CONFLICTS OF INTEREST}

Dr. Cunningham has acted as a paid consultant to Evolution Health Systems Inc., the owner of the Check Your Cannabis software platform. Mr. van Mierlo is the CEO of Evolution Health Systems Inc.

\section{REFERENCES}

[1] Ogborne AC, Smart RG. Cannabis users in the general Canadian population. Subst Use Misuse 2000; 35: 301-11.

[2] Hall W. The health risks of cannabis. Aust Fam Physician 1995; 24: $1237-40$.

[3] Hall W. The respiratory risks of cannabis smoking. Addiction 1998; 93: 1461-3.

[4] Cunningham JA, Bondy SJ, Walsh GW. The risks of cannabis use: Evidence of a dose-response relationship. Drug Alcohol Rev 2000; 19: $137-42$.

[5] Moore TH, Zammit S, Lingford-Hughes A, et al. Cannabis use and risk of psychotic or affective mental health outcomes: a systematic review. Lancet 2007; 370: 319-28.

[6] Macleod J, Oakes R, Copello A, et al. Psychological and social sequelae of cannabis and other illicit drug use by young people: a systematic review of longitudinal, general population studies. Lancet 2004; 363: 1579-88.

[7] Sanagan P. Up in smoke? The Challenges of cannabis for health promotion. Ontario Public Health Association eBulletin 2009[cited 9 February 2009]; Available from: http://www.ohpe.ca/ebulletin/ index.php?option=com_content\&task=view\&id=10262\&Itemid=78
[8] Cunningham J. Is level of interest among cannabis users in selfhelp materials and other services aimed at reducing problem use? Addiction 2005; 100: 561-2.

[9] Cunningham JA, Selby PL, Kypri K, Humphreys KN. Access to the Internet among drinkers, smokers and illicit drug users: Is it a barrier to the provision of interventions on the World Wide Web? Med Inform Internet Med 2006; 31: 53-8.

[10] Neighbors C, Larimer ME, Lewis MA. Targeting misperceptions of descriptive drinking norms: efficacy of a computer-delivered personalized normative feedback intervention. J Consult Clin Psychol 2004; 72: 434-47.

[11] Curry SJ, Louie D, Grothaus L, Wagner EH. Written personalized feedback and confidence in smoking cessation. Psychol Addict Behav 1992; 6: 175-80.

[12] Cunningham JA, Hodgins DC, Toneatto T, Rai A, Cordingley J. Pilot study of a personalized feedback intervention for problem gamblers. Behav Ther 2009; (in press).

[13] Humeniuk R, Ali R, Babor TF, et al. Validation of the alcohol, smoking and substance involvement screening test (ASSIST). Addiction. 2008; 103: 1039-47.

[14] Statistics Canada. Canadian Tobacco Use Monitoring Survey, CTUMS. 2006 [cited 2 January, 2008]; Available from: http:// www.hc-sc.gc.ca/hl-vs/tobac-tabac/research-recherche/stat/ctumsesutc_2006_e.html

[15] Substance Abuse and Mental Health Services Administration. Results from the 2002 National Survey on Drug Use and Health: Detailed Tables. 2003 [cited; 7 April, 2009]; Available from: http://oas.samhsa.gov/nsduh/reports.htm\#Standard

[16] SPSS Inc. SPSS for Windows, Version 15, 2008.

[17] Danaher BG, McKay HG, Seeley JR. The information architecture of behavior change websites. J Med Internet Res 2005; 7: e12.

[18] Internet World Stats. Internet World Stats: Usage and Population Statistics. 2009 [cited 2/11/2009]; Available from: http://www.inter networldstats.com/stats 14. htm

[19] Fox S. The engaged e-patient population: People turn to the internet for health information when the stakes are high and the connection fast. 2008 [cited 11 February, 2009]; Available from: $\mathrm{http}: / /$ www.pewinternet.org/pdfs/PIP_Health_Aug08.pdf 
[20] Cunningham JA, Sobell LC, Sobell MB, Agrawal S, Toneatto T. Barriers to treatment: Why alcohol and drug abusers delay or never seek treatment. Addict Behav 1993; 18: 347-53.

[21] Grant BF. Barriers to alcoholism treatment: Reasons for not seeking treatment in a general population sample. J Stud Alcohol 1997; 58: $365-71$.
[22] Humphreys K, Klaw E. Can targeting nondependent problem drinkers and providing internet-based services expand access to assistance for alcohol problems? A study of the moderation management self-help/mutual aid organization. J Stud Alcohol 2001; 62: 528-32.

(C) Cunningham and van Mierlo; Licensee Bentham Open.

This is an open access article licensed under the terms of the Creative Commons Attribution Non-Commercial License (http://creativecommons.org/licenses/by$\mathrm{nc} / 3.0 /$ ) which permits unrestricted, non-commercial use, distribution and reproduction in any medium, provided the work is properly cited. 